\title{
Sorrows of the young statistician
}

\section{Karl Pearson: The Scientific Life in a Statistical Age \\ by Theodore M. Porter \\ Princeton University Press: 2004. 352 pp. $\$ 35, £ 22.95$}

\section{Peter J. Bowler}

Karl Pearson was one of the founders of modern statistics and a major contributor to the creation of neodarwinian evolutionary theory. He was also a strong supporter of eugenics - the policy of 'improving' humans by controlling their reproduction. His contributions to science and mathematics were obscured by the hostility of some of the next generation of statisticians, notably R. A. Fisher. But more recently there has been a wider recognition of the part Pearson played in the rise of a statistical approach that has transformed our vision of nature.

Theodore Porter's book on Pearson is not a biography in the conventional sense. It focuses on the early part of his career in an effort to show how he was drawn to the study of statistics and eventually conceived it as the key to a new philosophy of nature, which was to become his life's work. Those seeking extended analysis of Pearson's work on statistics, evolutionary theory and eugenics will have to look elsewhere, because these have more to do with the later part of his career, which Porter surveys in a single, penultimate chapter. It is not Porter's intention to carry on, but this could easily

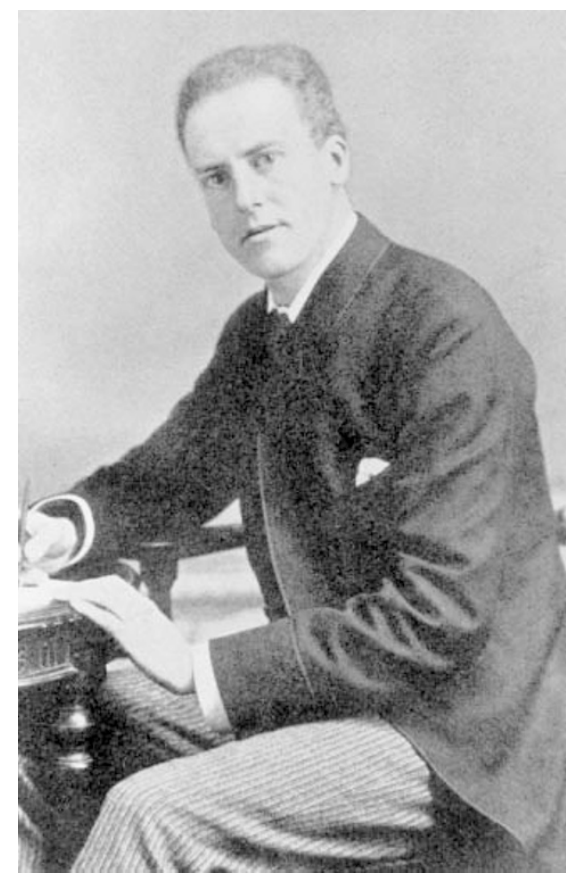

Karl Pearson's statistical analysis provided early support for Darwin's theory of natural selection.

be the first part of a two-volume biography.

The great value of Porter's book is that this focus on the early phase of Pearson's career highlights the complex route by which his quest for emotional and intellectual satisfaction led him towards the project that would, in effect, create modern statistics. This is very much the story of a romantic hero grappling with the challenges thrown at him by life and love. He studied mathematics at King's College, Cambridge, emerging as third wrangler in the mathematics Tripos (he was placed third in the lists of those com- pleting the examination), despite spending much of his time on other intellectual pursuits. These alternative interests led Pearson to study German culture, and he become an expert on the Reformation and passion plays. In 1884, though, he was appointed professor of applied mathematics at University College London, where he worked on the mathematical description of the behaviour of elastic bodies.

This hardly sounds the stuff of high romance, but Pearson was driven by inner passions to seek out a new vision of the truth and make his name by promoting it. In the course of his intellectual wanderings he became a socialist (although the story that he changed his name from Carl to Karl in honour of Karl Marx is apocryphal) and he took up 'the woman question' about women's rights. His relations with the opposite sex were mixed up in complicated ways with his intellectual and ethical interests, but his support for women's rights was genuine.

In addition to his post at University College London, Pearson was appointed to the Gresham chair of geometry in 1890 and began a three-year course of lectures to non-academic students in which his new approach to statistics was formulated. He chose statistics because by using familiar activities such as games of chance he could appeal to students who would not have appreciated a more abstract approach. For Porter, however, Pearson's 1892 book The Grammar of Science is the key statement of what was now emerging as a foundation for science itself. In 1893, the biologist W. F. R. Weldon approached Pearson for help with analysing his data on variation within

\section{Seeing the world}

Our senses allow us to see only a small fraction of our surroundings because we can detect only a narrow band of the electromagnetic spectrum. For more than a century we have developed technologies that have allowed us to create images using energies that exist outside these limits.

In Invisible Worlds: Exploring the Unseen (Weidenfeld \& Nicolson, £20), Piers Bizony has collected together a sample of the pictures produced by techniques such as cloud chambers, electron microscopes and modern telescopes. Along with more familiar scientific images, Bizony has included examples of the application of these technologies to our everyday lives, such as an ultrasound scan of an unborn baby and this snapshot of illegal immigrants, taken from a covert surveillance vehicle using backscatter $\mathrm{X}$-ray technology. The text that accompanies each picture explains the science behind the imaging technique.

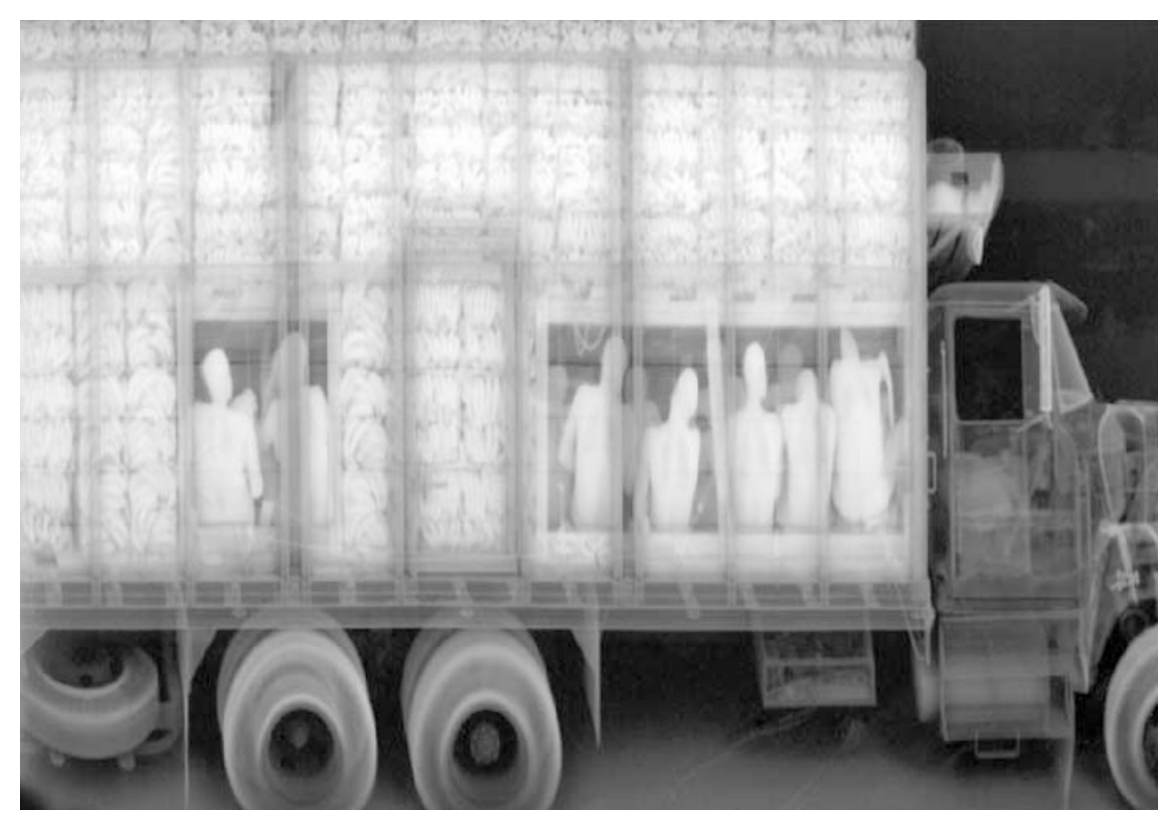




\section{Painting by numbers}

\section{Margaret Leiteritz turns scientific graphs into painted diagrams.}

\section{Martin Kemp}

Graphs are not generally considered to be things of beauty. Some of the lines that map typical behaviours of physical systems, such as the bellcurve beloved of statisticians, may have a certain visual charm, but the overall appearance of a graph in a scientific publication is not expected to incite aesthetic rapture. However, one of the jobs of artists is to see potential in, and take inspiration from, the most unexpected places, causing us to look afresh at something we take for granted. This is just what the German artist Margaret Leiteritz hoped to achieve with a series of paintings based directly on graphs in texts on chemistry and physics.

Educated first as a librarian, Leiteritz studied between 1928 and 1931 at the Bauhaus in Dessau, the school that was radically reshaping architectural thinking and all related fields of design. Her graduation diploma was signed by such luminaries as Mies van der Rohe, who directed the Bauhaus, Wassily Kandinsky, the Russian pioneer of abstract painting, and Paul Klee, the intellectual master of new and quirky pictorial vocabularies. This gives us an idea of the experimental environment in which she was immersed. After working in Dresden and Wuppertal, she was for many years librarian at the Engler-Bunte Institute at the University of Karlsruhe. But she continued to create art, pursuing a virtually secret career in which she developed a unique kind of painting.

Between 1961 and 1974, Leiteritz produced a remarkable series of 'painted diagrams', derived from a wide variety of the scientific articles and books in her care. She was particularly attracted to chemical engineering, and was fascinated by graphs that recorded phenomena of gases, liquids and solids, such as mixtures, solutions, reactions, liquefactions, viscosity, ignition and combustion. She transformed the linear diagrams into colourful, dynamic and engaging paintings, creating suggestive analogues for the life of the materials during the transformations they were undergoing. In effect, she created portraits of these processes, translating the conventions of graphs into pictorial

populations, as a test of the darwinian theory of natural selection. The pieces of the jigsaw puzzle now fell into place, and Pearson was soon pioneering his revolution in statistical thinking.

The end results of Pearson's intellectual pilgrimage are clear enough, but specialists may have doubts about the way Porter sees the whole package eventually coming together. Porter is not over-generous with references to the secondary literature, which makes it difficult to relate his interpretations to those published by other scholars. It is not always clear just how revolutionary Pearson's

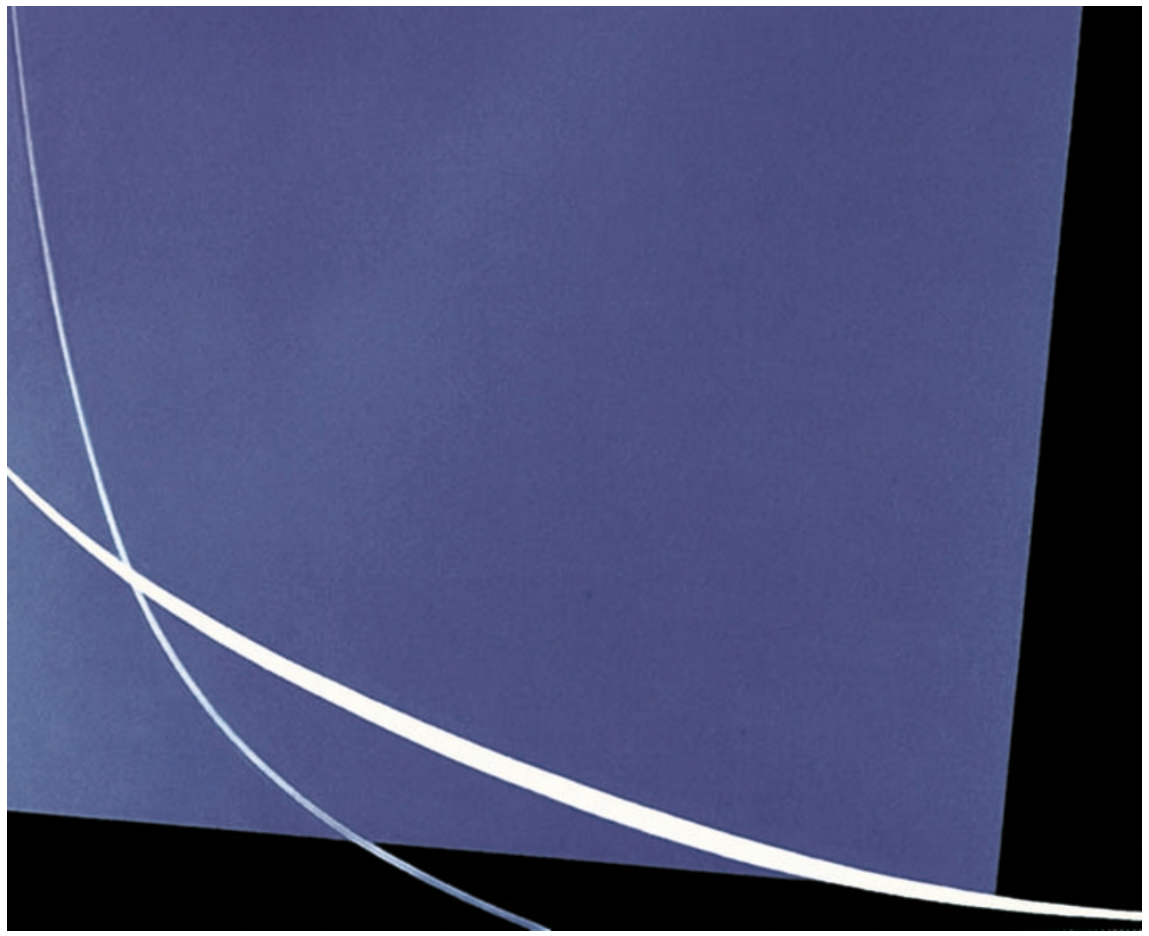

forces - much as Klee had translated the energies and motions of the Universe into line and colour, aspiring to create psychologically effective signs in a new kind of pictorial language. Her paintings, like those of Klee, are abstracted, but not abstract in the sense of not representing something.

One of Leiteritz's most elegant graph paintings, Crossing at the Left Border (shown here), painted in 1966, was prestigiously used on the cover of the catalogue for the exhibition 50 Years Bauhaus in Chicago in 1969. It was developed from figure 13 - "Separation as a function of flow rate with plate spacing as parameter" - of a paper entitled "Separation of liquids by thermal diffusion" by J. E. Powers and C. R. Wilke (in Am. Inst. Chem. Eng. J. 3; 1957). The mellifluous curves are closely transcribed from her source, and the colours and their tilted borders are designed to convey a sense of the dynamic separation processes induced by temperature. The materials that Leiteritz used -

new techniques were: Porter writes of him taking up mathematical statistics as though the field were already in existence, but some would argue that Pearson actually created the field in its modern form. Furthermore, Eileen Magnello has suggested (Hist. Sci. 37, 79-196, 123-150; 1999) that The Grammar of Science is not the best guide to the whole statistical project. And Weldon plays a disappointingly small role in Porter's book, considering that it was the problems generated by his data that helped Pearson complete his intellectual odyssey.

Porter's study is innovative because its oil on a linen-lined aluminum plate - sustain the technical tone of the image.

Leiteritz was trying to express that the graphs in the books and periodicals that passed through her hands were not inert and uninvolving records from specialist nooks and crannies of science; they were precious visualizations of the underlying actions of materials in nature, embodying the forces and forms that make up the patterns and rhythms of the world. To use a philosophical distinction, she said: "The diagram is not the thing in itself, but represents something that happens."

Her pictures can be seen at the Museum for Applied Art in Frankfurt, Germany, until 5 September, and are illustrated in Gemalte Diagramme: Die Bauhaus Künstlerin Margaret Leiteritz (Info Verlag, 1993).

Martin Kemp is professor of the history of art at the University of Oxford, Oxford OX1 1PT, UK, and co-director of Wallace Kemp Artakt.

focus on the complex nature of Pearson's early life provides a major counterweight to conventional studies of his later work in biology and eugenics. Whether his intellectual and emotional struggles made him the tortured outsider that Porter envisages is a moot point — most turn-of-the-century intellectuals were that way inclined, at least in Britain. But perhaps we should accept that with so complex a figure, differing interpretations are bound to emerge.

Peter J. Bowler is professor of the history of science in the School of Anthropological Studies, Queen's University, Belfast BT7 1NN, UK. 